Please do not remove this page

RMIT

UNIVERSITY

\title{
The affective commons of Coworking
}

Waters-Lynch, Julian; Duff, Cameron

https://researchrepository.rmit.edu.au/esploro/outputs/9921970609201341/filesAndLinks?institution=61RMIT_INST\&index=null

Waters-Lynch, J., \& Duff, C. (2021). The affective commons of Coworking. Human Relations, 74(3), 383-404. https://doi.org/10.1177/0018726719894633

Document Version: Published Version

Published Version: https://doi.org/10.1177/0018726719894633

Repository homepage: https://researchrepository.rmit.edu.au

(C) The Author(s) 2019

Downloaded On 2023/04/27 00:15:18 +1000

Please do not remove this page 


\title{
Julian Waters-Lynch $\mathbb{D}^{\mathrm{D}}$ and Cameron Duff \\ RMIT University, Australia
}

\begin{abstract}
What kind of common project is Coworking? Coworking was first presented as a novel model for organising autonomous, authentic and creative labour amid a community of workers who share these progressive aspirations. That this promise has not always been realised in practice has provoked a strong sense of ambivalence among many Coworkers. This article offers a critical assessment of this ambivalence, which we approach by way of a novel theoretical category, an affective commons. Such a commons describes the atmospheric product of the immaterial labour of Coworkers, including the 'commoning' processes by which the community endorsed in accounts of the appeal of Coworking may manifest. In this respect, ambivalence about Coworking may be regarded as an effect of conflicts that arise in the shared work of commoning, particularly conflict over the capture and commodification of pooled resources, and fair acknowledgement of the contributions labouring bodies make to their circulation and reproduction. We argue that this ambivalence emerges from Coworking arrangements themselves, rather than the broader conditions of precarity that characterise much nonstandard work. We close with a brief discussion of the practical implications of our analysis for ongoing efforts to address this ambivalence and sustain the mutualism of Coworking.
\end{abstract}

\section{Keywords}

Affective labour, ambivalence, atmospheres, commons, Coworking

\section{Introduction}

Work and organisation are changing in many parts of the world in ways that require new modes of thinking about the products and value of human labour (Kuhn et al., 2017). Digital technologies have untethered knowledge work from traditional sites

\section{Corresponding author:}

Julian Waters-Lynch, School of Management, RMIT University, 445 Swanston Street, Melbourne, VIC 3000, Australia.

Email: julianmaurice.waterslynch@rmit.edu.au 
of production, generating new challenges in managing the boundaries of working and non-working life (Jarvis and Pratt, 2006). Much attention has been paid to the intensification of information flows (Child and McGrath, 2001), but these changes in work and organising are marked as much by the prominence of affect and atmospheres as they are by novel communication technologies (Fotaki et al., 2017). This is why scholars have recently urged closer empirical investigations and fresh theoretical formulations of the relationship between affect, work, modes of organising and even novel forms of governance (Fotaki et al., 2017; Mühlhoff and Slaby, 2018).

The phenomenon of Coworking exemplifies the convergence of these trends and provides a rich context for their ongoing analysis. Coworking describes the varied practices of a heterogeneous collection of independent knowledge workers (rather than employees of the same organisation) sharing physical space, interacting and sometimes collaborating on shared projects (Gandini, 2015; Spinuzzi, 2012). What is produced in these arrangements, in the mingling of human, technical and material infrastructures, may entail a material object, an immaterial service, a mesh of social and professional relationships, an affective state or an atmosphere (Blagoev et al., 2019; Jakonen et al., 2017; Merkel, 2015). Such developments have provoked interest in the 'immateriality' (Lazzarato, 1996) of Coworking, and the mix of human and nonhuman forces, objects, relations and qualities that converge in this work (Cnossen and Bencherki, 2018; Gregg, 2018; Lee, 2019). Equally important has been interest in the relationships established between Coworkers, ${ }^{1}$ and the pervasive veneration of the notion of 'community' by Coworking protagonists to explain the core value proposition and organising principle of Coworking (see Capdevila, 2014; Garrett et al., 2017; Spinuzzi et al., 2019 for reviews).

While community can be a contentious term when applied in contemporary urban contexts, charged with appearing everywhere and nowhere at once (Bauman, 2001), its frequent invocation to explain Coworking's appeal directs our attention towards the immaterial concatenation of relationships, practices, symbols, subjective meanings and felt experiences that describe the everyday activity of Coworking, rather than the materiality of office infrastructure and amenities. Pondering these immaterial aspects has occupied much recent scholarly analysis of Coworking. Some look optimistically towards Coworking's potential for innovation and entrepreneurship (Bouncken and Reuschl, 2018; Capdevila, 2018; Merkel, 2017), identifying a role for Coworking in the provision of social support for contemporary knowledge workers seeking to manage the vicissitudes of nonstandard work (Gerdenitsch et al., 2016; Merkel, 2019). Others are more wary of the uncritical veneration of creative and entrepreneurial work, concerned that this obscures the endemic precarity that characterises the life circumstances of many Coworkers (Gandini, 2015; Gregg and Lodato, 2018). Indeed, much empirical analysis of the experience of Coworking reveals a strong sense of ambivalence among Coworkers, involving acknowledgement of the model's appeal coupled with unease about its typical modes of organisation and practice ${ }^{2}$ (De Peuter et al., 2017; Richardson, 2017).

Interrogating the character and conditions of this ambivalence is the key aim of this article, which we approach by way of a novel theoretical category, an affective commons. We argue that such a category is needed in order to more meaningfully account for both the ambivalence widely reported in contemporary studies of Coworking, and the equally central invocation of community. The contention that the former is merely a function of 
precarity, while the latter is a farrago of misguided optimism is inadequate in our view. To begin with, we would distinguish between ambivalence about the general conditions of nonstandard work, and ambivalence about Coworking arrangements more specifically. The claim that the ambivalence expressed by many Coworkers reflects the broader precaritisation of nonstandard work (see De Peuter et al., 2017; Gregg and Lodato, 2018) is compelling, yet it arguably fails to account for two key features of Coworking identified in the literature. First, it is possible for individuals to feel deeply ambivalent about the precarious conditions of nonstandard work in general, and yet retain entirely positive views about the particular Coworking site they frequent, and the model of Coworking itself more abstractly (Martin, 2016; Merkel, 2019). Second, reliance on the notion of precarity to explain the ambivalence reported by some Coworkers overlooks the fact that many embrace Coworking in full cognisance of this precarity. Moreover, it is routinely reported that individuals may leave secure organisational employment for the uncertainties of self-employment and the prospects of more meaningful work, only to encounter novel problems for which Coworking presents as a potential solution (Lee, 2019; Richardson, 2015; Waters-Lynch, 2018). Coworking may thus offer a means of managing precarity, rather than always remaining a function of it. In any event, nonstandard work and Coworking are distinct phenomena. One can feel economically secure and work in a Coworking space, or experience precarity in nonstandard employment but not Cowork. Hence, it is the expression of ambivalence about Coworking itself that requires closer examination.

Our aim is to provide this explanation by way of the notion of an affective commons. Such a commons describes the atmospheric product of the immaterial labour of Coworkers, including the 'commoning' processes (De Angelis, 2017) by which the community often endorsed in discussions of the appeal of Coworking manifests. Coworking communities may, in this respect, be treated as an expression of the commoning by which uniquely pooled resources are generated. Ambivalence about Coworking may, in turn, be regarded as an effect of conflicts that arise in this commoning, particularly conflict over the capture and commodification of common resources, and due acknowledgement of the contributions individuals make to their circulation and reproduction. This explanation has the advantage of identifying the causes of reported ambivalence about Coworking itself, rather than in the broader conditions of precarity that might be said to prevail in much nonstandard work (Gill and Pratt, 2008). More directly, this ambivalence may be said to stem from inadequate responses to the distinctive 'social dilemma' (Ostrom, 1990) encountered in an affective commons, insofar as this dilemma involves conflict over the immaterial production and distribution of the social, affective and material resources generated in Coworking spaces. In proposing a third wave of the commons, we will cite liberally from existing discussions of the commons (De Angelis, 2017; Lessig, 2003; Ostrom, 1990) for insights into the difficulties of managing an affective commons, and the unique governance challenges such a task is likely to entail.

Central to these governance challenges are the pooled resources that give rise to the principal social, affective and material instantiations of an affective commons (see also Jakonen et al., 2017). These resources encompass the mix of informational and material resources, sociality and affective climate that are central to the ways Coworking is 
formally and informally organised (Blagoev et al., 2019; Cnossen and Bencherki, 2018). In discussing these resources, and the characteristic features of an affective commons more broadly, we will be guided by recent work proposing novel means of thinking, feeling and writing about affect (see Ashcraft, 2017; Knudsen and Stage, 2015; Stewart, 2007; Vannini, 2015). This work will frame our discussion of affect and affective labour, and our view that affective commons are, at least in part, co-constituted through the affective labour of human participants. The literature on affective atmospheres (Anderson, 2014) will further inform our discussion of the resources generated in this commoning as bodies (human and nonhuman) labour together. We cite this literature to emphasise the ways Coworking captures a collective experience that is consumed at the same time as it is produced. Finally, we will briefly assess the implications of our analysis for the business model of Coworking, and the challenges an affective commons presents for its sustainable management and renewal by groups engaged in its production and consumption.

\section{The ambivalent sociality of Coworking}

Shared office arrangements between individuals, even formalising lease arbitrage as a distinctive business model, was not a new phenomenon when the term Coworking was first used in 2005 (Kojo and Nenonen, 2017). Rather, the qualities that first distinguished Coworking from similar arrangements, and framed much of its early appeal, lay in its informality, the centrality of its valorisation of community and its bespoke, post-Fordist, Do-It-Yourself aesthetics. These qualities invoked post-bureaucratic visions of how work might be different (e.g. Jones, 2013), of a working life more purposeful, autonomous, authentic and creative, and how Coworking arrangements might help assemble and organise encounters between a community of workers who shared these progressive aspirations (Sundsted et al., 2009). In approaching the apparently contradictory logics of 'working alone, together', many have observed the diversity of relational models in different Coworking spaces, noting typologies of 'good neighbours' and 'good partners' (Spinuzzi, 2012), or distinguishing transactional, cost-based collaboration from more intimate, 'relational collaboration' (Capdevila, 2014). Interestingly for our purposes, discussions of community in Coworking spaces often emphasise how Coworkers themselves contribute to this sociality, through for example, distributed curatorial practices that create a 'collaborative atmosphere' (Merkel, 2015: 121); welcoming, sharing and introducing practices that blend professional and personal boundaries; or endorsing, encountering and engaging practices that sustain a sense of community (Garrett et al., 2017), even if the imprecision with which the term community has been applied in these discussions has attracted strong criticism (Spinuzzi et al., 2019).

In thinking about the endorsement of community in existing accounts of the practice and appeal of Coworking, we are not the only ones to link Coworking with discussions of the commons. An early popular account introduced the concept as a 'triumph of the commons' whose key lesson is that 'sharing is good' (DeGuzman and Tang, 2011: 7). Indeed, a number of scholars have categorised Coworking as part of an array of "new urban commons' initiatives such as community gardens and art projects (De Peuter et al., 2017; Merkel, 2015), and there are documented cases of 'community-led 
Coworking spaces' that explicitly describe attempting to manage 'a commons' (Avdikos and Iliopoulou, 2019). But these examples are rare exceptions in the literature on Coworking, and none substantively engage with the theories of commons, the nature of the resources produced through common efforts or the distinct social dilemmas germane to their production, circulation and/or valorisation. More often the empirical literature simply attests to a feeling of shared commitments to a common project among Coworkers (Blagoev et al., 2019; Garrett et al., 2017; Merkel, 2015), while noting that these feelings are difficult to sustain over time (De Peuter et al., 2017; Morgan and Woodriff, 2019).

More generally, the existing literature describes a set of ambivalent attitudes about Coworking, acknowledging both the appeal of the model alongside disappointment with some aspects of its realisation (De Peuter et al., 2017; Lee, 2019). The puzzle of this ambivalence is either offered as part of a call for further research, or dismissed as a more general function of the insecurity and structural vulnerability typical of nonstandard work (as detailed for example by Gill and Pratt, 2008; Hesmondhalgh and Baker, 2011; Sennett, 2007). Thus, the argument goes, whatever traces of informal mutualism may initially have been visible within Coworking (Merkle, 2019), can only wilt under the looming spectre of neoliberalism with its pervasive insecurities (Bandinelli, 2019). While we do not disagree with these concerns about the precarious nature of much nonstandard work, these critiques locate the source of the problem beyond the structure of Coworking relations, in broader political and economic contexts seemingly beyond reach. They also dismiss any lingering aspirations towards mutualism among Coworkers as a futile project, while apparently obviating the need for any further attention to the internal issues of value creation, maintenance and capture within Coworking arrangements. In place of this view, we offer an alternative explanation for the ambivalence documented in so much of the Coworking literature, rooted in the shared production of affect and atmospheres, and their management as a common resource vulnerable to depletion, dispersal, commodification and capture. Theoretically, we believe this approach offers a more nuanced explanation of the dynamics of allure and frustration attested to within the empirical literature on Coworking. Practically, we argue that greater sensitivity to the management of affect and atmospheres as common resources offers a constructive path for those interested in rehabilitating and sustaining Coworking as a commons-oriented project.

\section{Affects and atmospheres: The resource pool of an affective commons}

We regard ambivalence about Coworking identified in the literature to be an affective condition resulting from tensions arising from the generation and distribution of shared resources within an affective commons. Our first step in developing this argument, and our analysis of the unique social dilemma peculiar to an affective commons more broadly, is to identify the commoning processes by which these shared resources are generated. In the first instance, we will approach this task by way of the literature on immaterial and/or affective labour (Oksala, 2016). This literature will help frame our analysis of the commoning practices by which shared resources are generated, distributed and adopted 
within an affective commons. In a seminal contribution, Maurizio Lazzarato (1996: 133) characterises immaterial labour in terms of the production of 'informational and cultural content' whereby 'cultural and artistic standards, fashions, tastes, consumer norms, and more strategically, public opinion' are defined or 'fixed'. While this analysis, and its endorsement in the influential work of Hardt and Negri (2000, 2004), has inspired sustained criticism (Dowling et al., 2007; Oksala, 2016), the broader characterisation of a shift from material to immaterial labour in advanced economies, from the production of things, to the generation of symbolic content, is now widely accepted.

A key feature of almost all recent discussions of immaterial labour, and its role in the transformation of work in particular contexts, is an emphasis on the collective work of manipulating relations between actors, forces and signs; what might be called work as affective relation (Cameron, 2018; Oksala, 2016; Weeks, 2011). For Lazzarato (1996: 136), immaterial labour 'exists only in the form of networks and flows', yielding "first and foremost, a "social relationship" (a relationship of innovation, production and consumption)'. Echoing this view, Hardt (1999: 95-96) argues that immaterial labour, and the affective labour of which it is partially comprised, necessarily entails the production of subjectivity, affects and modes of sociality, such that labour is increasingly valorised in terms of the affects, subjectivities and social relations it produces or enables. Hardt (1999: 97-98) goes on to offer a tripartite account of immaterial labour comprising the 'informationalization' of productive manufacturing, the 'immaterial labour of analytical and symbolic tasks' and the 'production and manipulation of affects' (see Hardt and Negri, 2004: 108-112). We will dwell on this third aspect for its insights into the products of immaterial labour in Coworking contexts, and for its account of the links between immaterial labour and subjectivity, which will be crucial for the analysis that follows in later sections where we discuss the generation of pooled resources in an affective commons.

Hardt (1999: 98) regards affective labour as a 'form-of-life'. It works 'directly on the affects: it produces subjectivity’ (Hardt, 1999: 99). These insights have spawned a host of novel empirical investigations of the character of affective labour in diverse work contexts, and of the particular subjective and social forms this labour generates (see Cameron, 2018; Kenny and Fotaki, 2014; Weeks, 2011). Much of this work takes important methodological and conceptual cues from Arlie Hochschild's (2012 [1983]) celebrated account of the emotional labour of airline staff, and the welter of studies of emotional labour in diverse settings that have followed (see Iszatt-White, 2013). Yet while Hochschild's study, and many that have followed, have emphasised the emotional work of immaterial labour in advanced economies - understood in terms of a more or less conscious presentation of specific, recognisable emotions, reactions, mood states, demeanours or feelings - a focus on affective labour arguably invokes a deeper ontological register by emphasising the very production of subjectivity (Hardt and Negri, 2004; Oksala, 2016). Useful examples of this focus include studies of 'greeters' and/or concierge staff in hotels, bars and restaurants, and the affective labour by which staff attempt to embody the subjective identities that the venue seeks aspirationally to project (Coffey et al., 2018; Dowling, 2012). Much of this work describes the affective labour of generating, sustaining and personifying a 'vibe' by which a particular establishment may be differentiated from market rivals. Staff, in these examples, undertake the labour 
of affecting a 'cool', 'hip' or otherwise desirable subjective identity, just as they labour to stimulate an atmosphere with very particular affective and aesthetic valences (Cameron, 2018; also Coffey et al., 2018). Other studies have offered similar insights into the valorisation of affective labour in media, advertising, film, music and/or television production (Hesmondhalgh and Baker, 2011; Hoedemaekers, 2017). This work typically traces the transmission of affective labour in media and the way it promotes novel forms of 'affective attunement' between bodies, objects and entities (Papacharissi, 2015). This attunement commonly involves the creation of new social collectives, such as fan cultures, social and political 'publics' or niche audiences (Blackman, 2019), while also serving to create affective and subjective identifications between consumers and producers of content, which may further reinforce brand identifications, political allegiances and/or sub-cultural affiliations (see Madison et al., 2009; Hesmondhalgh and Baker, 2011; Kuhn et al., 2017).

What these studies share is a focus on the relational and processual generation of value in and through the work of affective labour, where this value may be understood either affectively in terms of the generation of specific affective states or atmospheres, or subjectively in terms of the expression or realisation of specific subjective qualities and identifications. These lines of analysis lead to novel ways of thinking about the products of affective labour, just as they lead to new ways of thinking about how these products are consumed. They are central, for these reasons, to our elaboration of the pooled resources generated in and through Coworking, and the affective commons that these resources collectively instantiate. Cameron's (2018) work for example points to the production of a particular atmosphere as a function of the unique affective labour performed by staff (and patrons), and the ways this 'vibe' is consumed by patrons as it is converted into a kind of subjective expression of social distinction (see also Coffey et al., 2018). This conversion, we should add, is central to the valorisation of affective labour in the hospitality sector, functioning as a kind of affective 'surplus value' in Massumi's (2018) terms that underscores the profitability (or otherwise) of particular venues. Papacharissi's (2015) work offers similar insights into the role of affective labour in the production of media content, and how the consumption of media is increasingly attuned to the expression of novel forms of affective and subjective identification and affiliation, and their valorisations in consumption. In the same vein, Lisa Blackman (2019) has recently described how new media progressively functions as an affective economy for the distribution of structures of feeling.

Yet for all of these insights, it is still unclear how the collective content of affective labour, the things, values, affects and subjective identities that it produces or expresses, ought to be understood. We would argue that compelling indications of this productive force may be gleaned from the cognate literature on 'affective atmospheres' (Anderson, 2014), which is slowly finding its way into discussions of immaterial labour, including the analysis of Coworking (see Gregg, 2018; Jakonen et al., 2017). Indeed, by focusing on the modulations of a body's capacities to affect and be affected in the spaces and times of its encounters, work on affective atmospheres avails a means of tracing some of the mechanisms by which common resources ebb and flow in Coworking spaces. To begin with though, affective atmospheres at once describe a particular quality of the environment from which they emanate (Anderson, 2009: 79-80), just as they require a sentient subject 
for their signification, their coming into meaning (Bille et al., 2015: 32). As Anderson (2009: 80) explains, affective atmospheres 'bear a characteristic spatial form - diffusion within a sphere [. . .] generated by bodies - of multiple types - affecting one another as some form of "envelopment" is produced'. In this 'envelopment', affective atmospheres manifest a store of action-potential that mediates the dispositions and agencies potentially enactable in these spaces, further inflecting a body's power of acting. Atmospheres give social and material form to diverse structures of feeling while also mediating a body's capacity to act in response to these states (Bissell, 2010: 272-275).

Affective atmospheres thus describe the collective products of bodies (human and nonhuman) acting together, encountering one another, affecting one another, producing a shift in the atmospheric tone of a space and so transforming what bodies might be capable of producing in concert within that space. This focus on the co-constitutive enmeshing of bodies, spaces and forces provides unique insights into the affective products of Coworking, inasmuch as the study of Coworking inevitably foregrounds a common space of activity, the Coworking site. Greater attention to the spatial and affective coordinates of this common activity helps to explain what is collectively produced in Coworking spaces. In our view, this commoning yields diverse social, affective and material resources that circulate in space, mediating what bodies can do, as this mediation further inflects the ways resources are produced and reproduced in such a commoning of space. This common pool of resources emanates from collective activity, inflecting bodies with novel capacities, new modes of interaction, new insights, tendencies or habits, new creative opportunities, a different experience of work (see Jakonen et al., 2017). Whether or not this novelty may be productive of value or more disruptive depends entirely on the character of the atmospheres generated in encounters and the common resources they yield.

Affects, and the atmospheres they are imbricated in at work, do not express a potential for being affected, for feeling, thinking or doing; they describe the actual processes in which bodies become capable of these activities (Pile, 2010). This is what we mean when we describe affective atmospheres as a common store of pooled resources, inasmuch as atmospheres affect bodies, transforming their capacities, just as bodies affect atmospheres, tempering their tone, inflecting their collective feeling and the meanings associated with them. Melissa Gregg's (2018) recent work provides strong examples of how affective atmospheres inspire, suggest or provoke specific kinds of embodied experience - a kind of co-constitution of subjectivity - in Coworking sites. She argues that these sites appeal to prospective participants (or customers) to the extent that they cultivate the 'right atmosphere' that makes individuals 'feel close to something - something that might be happening' (Gregg, 2018: 89 emphasis in original). This incipient 'happening' is the activity of the space's atmosphere; the sense that new encounters, leads, ideas, collaborations, friendships and romances might be possible within it. Gregg (2018: 87) speaks of how by joining a space 'coworkers invest in an infrastructure for the development of new identities, affiliations and rituals'. We would assess this infrastructure in social and affective terms, as an atmosphere in which the social, affective and material resources necessary for the successful realisation of the transformational projects individual Coworkers aspire to are generated, stored and made available for circulation. This is the key significance of an affective commons understood in 
atmospheric terms, capturing the way Coworking spaces sustain diverse atmospheres that might offer resources for the realisation of particular projects. It is important that we add that while all spaces might be said to have an atmosphere, only the presence of a community with an interest in the quality of the atmosphere as a shared resource renders its conception as a commons analytically useful in the work of explaining the nature and effects of Coworking. However, like all common pool resources, a community attempting to share these atmospheric resources as an affective commons will yield its own distinct set of social dilemmas.

\section{A third wave of commons theory}

So far, we have argued that atmospheres play a vital role in shaping the 'structures of feeling' encountered through Coworking, including the experiences of connection, identification and belonging routinely described in the empirical literature. These atmospheres are a collective function of both the environments of Coworking sites and the commoning efforts of Coworking participants. The welcoming, endorsing, encountering and curatorial practices maintained by Coworkers (see Garrett et al., 2017; Merkel, 2015; Waters-Lynch, 2018) certainly play a role in forming and maintaining these atmospheres, but bodies also attune more subtly to the affective resonances, intensities, rhythms and contagions of the atmosphere itself. These resonances pool in an affective commons. Recognising these atmospheres as a constituent store of resources, albeit of a subtle kind, draws attention to their 'infrastructural' (Frischmann, 2012) role in the production of immaterial flows of value (Lazzarato, 1996) that shape the subjectivities and sociality equal to the demands that entrepreneurial and knowledge work economies impose. Moreover, framing these atmospheric resources as a commons draws attention to the complex, iterative and ramifying relationships between their production and consumption. And while atmospheres are lived in and moved through (Sumartojo and Pink, 2018) rather than 'consumed' like tangible products per se, their affective tone can be either depleted, modified or recharged through the presence and actions of inhabitants in their encounters within them. In these respects, an affective commons draws attention to the problematic relationship between the creation and value of these resources and their commercial valorisation. Tensions between the social production of affective atmospheres and their commodification and private capture explain, in our assessment, much of the ambivalence towards Coworking described in the literature to date. However, just as recent work has reconsidered the relationship between commons, crises and social and technological innovation (Arvidsson, 2019), resolving these tensions could spur fruitful directions for innovation.

We must stress that in posing the notion of an affective commons, we build upon two prior waves of literature, residing in different disciplines, that describe the management of common resource pools, and address the distinct governance challenges faced by the communities that consume, maintain and produce them. The first wave was pioneered by the political economists Elinor and Vincent Ostrom, who inaugurated and legitimised the theory of common pool resource management in the early 1970s. The Ostroms challenged the prevailing view that open access resource arrangements would inevitably lead to free rider problems (Olson, 1965) or tragedy of the commons scenarios (Hardin, 1968), by 
pointing to an abundance of empirical examples where local communities sustainably managed natural resources without relying on the formalised arrangements of individual ownership rights, or the administrative control of the state. By highlighting how communities with appropriate norms can effectively manage common resources, they challenged the underlying assumptions about human motivation, the sense of the inevitable fallibility of cooperative logics, and the binary notion that resources should either be privatised or brought under state control (see Ostrom and Ostrom, 1977).

The second, 'networked information' wave of commons theory began in the mid1990s, principally led by a small group of legal and media scholars studying internetmediated sharing practices and their governance arrangements (e.g. Benkler, 2002, 2006; Madison et al., 2009, 2014; Lessig, 2002). While focusing on the voluntary labour evinced in internet-mediated collaborative projects such as open source software, these scholars shared Ostrom's insistence that a diverse range of motivations can drive social and economic cooperation and production beyond narrow financial incentives (Benkler and Nissenbaum, 2006) and that neither markets, firms nor governments exhaust the range of options for optimally managing complex resource production and access arrangements (Benkler, 2002). These second wave scholars pointed out important differences between the pre-industrial natural resource commons studied by Ostrom, and the post-industrial, networked knowledge commons studied by Benkler, Lessig and others, not only in the nature of the resources themselves but in the social dilemmas their governance models must address. The first difference relates to the consumable nature of the resources themselves. Natural resources like forests, fisheries and pastures are depleted when used, and thus are sensitive to overexploitation, and can even be destroyed if managed carelessly. This was of course the premise of the argument against open access arrangements espoused in Hardin's 'tragedy of the commons'. The governance dilemma for the shared resources studied by Ostrom hinged upon managing access to 'rivalrous goods' through institutional norms that guided sustainable consumption. And yet, Hardin's overgrazing analogy, central to this dilemma, is fundamentally misplaced in the context of the information sharing practices observed by scholars in the networked school. This is because information is nonrivalrous. Learning something, or 'consuming knowledge', does not subtract from another's ability to use it. In this respect, the networked information scholars correctly diagnosed how new digital infrastructures were radically transforming the marginal cost of reproducing information once it has been created and codified (Benkler, 2002; Lessig, 2002). This transformation has been at the heart of the digital disruptions that have faced enterprises engaged in producing and distributing knowledge and creative work through tangible artefacts such as newspapers, books, records and videos (see Benkler and Nissenbaum, 2006; Frischmann et al., 2014).

But while the cost of reproducing knowledge codified in digital formats might be minimal (Rifkin, 2014), the cost of discovering and creating new knowledge or artistic works remains high. Thus, as these second wave scholars have pointed out, the social dilemma at the heart of digital knowledge commons is not about managing sustainable exploitation of a naturally existing resource, but the artful curation of institutional logics that encourage sustainable creation and renewal of knowledge resources. This challenge calls for a system of fair attribution for the costs of knowledge production, and 
meaningful safeguards against forms of enclosure or appropriation of the collectively produced resources. Visible exploitation of knowledge resources, where the benefits of the efforts of a majority are captured by a minority, tend to erode the motivations for ongoing commons-based knowledge production and refinement (Benkler, 2017). This is why regimes of patents and intellectual property rights such as the Creative Commons licence, first developed by Lawrence Lessig (2003) and others, have been the focus of debate for these scholars, turning on questions of how to balance the design of economic systems that sustain individual motivations towards the labour of knowledge production while maximising the social benefits that result from open access to this knowledge.

Many of these second wave scholars were responding to Lazzarato's (1996) purported 'great transformation' in the valorisation of economic production, offering an important counternarrative to the dominance of market logics in the digital era, but their models of 'commons-based peer production' (Benkler, 2006: 60) best fit knowledge pools rendered in codified, digital formats. They address the 'informationalisation' component of Lazzarato, Hardt and Negri's models but offer little insight into the 'production and manipulation of affects'. Indeed, neither the first nor second waves of commons research addresses the distinct features of affective labour and atmospheres in ways that might shed light on the production of value in Coworking spaces. This is why we propose a third category of commons, an affective commons, in which bodies co-produce, interpenetrate and are submerged within an atmosphere of pooled affective resources. Crucially, in addition to the (affective) labour required for its cultivation and promotion, an affective commons is sustained in the periodic mobilisation of human (and sometimes nonhuman) bodies as they interact in relations, practices and/or encounters that recharge the atmosphere and replenish the pooled resources it sustains.

The extant empirical literature on Coworking has documented the labour involved in cultivating appealing, productive, welcoming or inclusive atmospheres, and its distributed, collective production by Coworkers themselves (Blagoev et al., 2019; Garrett et al., 2017; Merkel, 2015, 2019; Vidaillet and Bousalham, 2018; Waters-Lynch, 2018). The ethnographic accounts in this literature describe formal sharing rituals, most often through the joint preparation and consumption of food, alongside informal practices including various welcoming gestures, smiles and verbal greetings, laughter, expressions and nonverbal performances of curiosity, encouragement, support and other emotions. These accounts also chronicle curatorial activities such as the labour of cultivating an atmosphere by tending to plants and decorations, posting on bounded social media channels or arranging physical artefacts in the spaces. These ongoing interactions and communal labour can be understood as processes of commoning (De Angelis, 2017) and are emblematic, in our view, of the affective labour required to sustain an affective commons. While the affective timbre of these activities has been observed by others (Gregg, 2018; Jakonen et al., 2017; Merkel, 2015), here we seek to elevate the analysis beyond individual sites and activities by emphasising what is collectively produced through these practices. We should also emphasise how the nature of these pooled resources differs from both the shared tangible goods and digitised information described by the prior literature on commons. This is the contribution we would highlight in characterising these shared atmospheric pools and the community that sustains them as an affective commons. 


\section{The affective commons}

The affective atmospheres that partially constitute an affective commons are, by their nature, shared. Their composition, dispersion, eruption, transformation and dissipation are (in part) crafted, sustained and replenished by their (human) occupants (Bissell, 2010; Sumartojo and Pink, 2018). Construed as an affective commons, affective atmospheres suffer what might be called an evaporation rate, insofar as the failure to maintain the necessary labour of extending and sustaining such atmospheres inevitably results in their dissipation, along with the common resources they instantiate (see also Billie et al., 2015). Whereas 'congestion' is often viewed negatively for many public goods, an affective commons relies on an affective density, a kind of social and material congestion of bodies, actors and forces to remain vibrant (see Duff, 2014). Our notion of an affective commons offers a theoretically grounded explanation for what is commonly described in the vernacular as the 'buzz' or 'vibe' of a Coworking site, and a more precise account of the compositional dynamics of a place 'losing a (positive) vibe'.

It is important to acknowledge that scholarly work that examines how these atmospheres are cultivated, understood or 'attuned' is still in an early phase (Sumartojo and Pink, 2018; Thibaud, 2015). The literature on physical and digital commons demonstrates how the distinctive properties of each phenomenon harbour different 'social dilemmas' (Ostrom, 1990), and thus necessitate unique strategies for their management and governance. Guided by these insights, we regard ambivalence towards Coworking to be a distinct manifestation of the social dilemma endemic to the affective commons. What we mean is that the social dilemma at the heart of an affective commons concerns the task of encouraging ongoing practices and interactions that habitually recharge the shared atmosphere that animates this commons, and the social, affective and material resources it yields for Coworking participants. These shared resources are central to the value proposition of Coworking ventures (see Gregg, 2018; Jakonen et al., 2017), even though the means of recognising and effectively governing these resources point to a new set of problems for these ventures, just as they suggest an emerging frontier for research in studies of organisation and affective labour more broadly. Indeed, our analysis touches on divergent valorisations of immaterial and affective labour in contemporary market relations, with particular regard to its social and collective aspects (Anderson, 2016). The questions and controversies raised by the affective commons thus need not be limited to Coworking, but can be applied to other sites where immaterial labour plays a role in changing the character of work.

Another way of looking at the social dilemma endemic to Coworking is to note how co-consuming a shared resource, whether natural, informational or affective, requires people to encounter by-products of each other's consumption. Congestion, pollution, overuse, free-riding and conflict are all externalities that can stem from the mismanagement of the shared consumption or production arrangements of collective action problems (Olson, 1965). Addressing these social dilemmas involves resolving the tension between individual and collective rationality. Prior to the work of Ostrom, the 'prisoner's dilemma' and 'tragedy of the commons' had become near mythic parables that purported to explain situations where the pursuit of individually rational strategies results in situations where everyone is worse off (Kollock, 1998). Why would an individual choose to 
cooperate when she might gain more by defecting? Why would one labour to create a resource when he could leave this work to others and still benefit from its consumption? Despite these problems, scholars developed theories of the commons by examining cases where these models, or at least some of the assumptions they are predicated upon, do not fit with empirical observations, and fail to predict the outcomes of activity. Not all social worlds resemble jails, and not all actors lack concern for the welfare of others, or the agency to influence the norms and rewards that govern collective action (Kollock, 1998). Even game theoretic experiments have found interactions converge towards mutual cooperation in instances where the same actors engage over time and, most pertinently, when their actions are made visible to others (Axelrod and Hamilton, 1981). In such cases, community members communicate with each other, develop cooperative agreements and coordinate their actions. All of this has been observed in empirical studies of specific Coworking sites. While adding more 'players' to a game can make cooperation more difficult (Axelrod and Dion, 1988), much hinges on whether the effects of individual actions are visible, and the 'rules of the game', or practical logic of the situation, can be understood and altered by participants (Kollock, 1998).

Ostrom's core contribution was to illustrate how some communities manage these potential dilemmas by crafting bottom-up norms that attend to problems as they arise. Her work demonstrates that community-governed commons are possible, but also that their management is delicate and, like all economic and political organising regimes, are vulnerable to threats. An 'immense number of contextual variables' can influence these outcomes, but both the capability of the community, its size, heterogeneity, cultural repertoire, social capital and leadership, and the nature of the shared resource itself, including the labour required for its creation, its relative scarcity, rates of depletion and regeneration, all play a part in the viability of a commons (Ostrom, 2000: 148). This is why she called for closer empirical examination of the detailed circumstances where commons are sustained and when they fail. Such scrutiny distinguished the second wave literature on human created knowledge commons from the first wave on natural resource commons, just at it further guides the distinction for a third wave of literature on affective commons that we propose here. Because atmospheres have their own distinct dynamics of creation, expansion, modulation, dispersal and depletion, which differ from the shared information pools of the second wave, the maintenance of an affective commons will require different management tactics to sustain their constitution and appeal.

\section{Challenges for practice: Management and governance of an affective commons}

The concept of a commons does not simply refer to a shared resource, but the relationship between a community, an ethos and a resource (Arvidsson, 2019). The latter hints at a series of governance challenges that are likely to prevail in an affective commons. The first relates to the means of sustainably managing an affective resource, in essence to ensure its rate of depletion does not exceed its regeneration. For example, what is the relationship between atmospheric density and community size? What comprises free riding for a common atmosphere and what are its consequences? How might negative modulation of affect in an atmosphere - or 'pollution' - be accounted for? The second 
challenge involves the self-governance strategies that a community might employ in order to sustainably manage such a resource. Our argument has been that ambivalence about Coworking largely stems from an inattentiveness to these processes of value creation, consumption and capture as they relate to Coworking atmospheres. While shared dynamics of production and consumption are germane to all common atmospheres, Coworking is characterised by the enclosure and commodification of an atmosphere by way of a distinctive business model. In other words, the business of Coworking highlights a gap between value and valorisation. This is why we argue that the recognition of Coworking atmospheres as an affective commons not only offers a more nuanced descriptive analysis, but also opens up a set of ethico-political considerations regarding the governance arrangements and dominant business models of Coworking.

In the digital world, the user generated content models of many Web 2.0 platforms have attracted critical attention for their enfolding of the 'free labour' of user content creation within models of commercial valorisation (Acquier et al., 2017; Beverungen et al., 2015; Scholz, 2016). We suggest an analogy in the relationship between the user generated affective appeal of Coworking and its private capture and commodification by the enterprise. Research has long demonstrated that people feel uneasy upon encountering imbalances in fair exchange for labour, even if the specific behavioural responses to these imbalances can differ between individuals (Adams, 1965; Huseman et al., 1987). The elusiveness of affective labour can render its products difficult to account for and contest (Gregg, 2018), although this should not dissuade us from efforts to identify and respond to the key problems encountered in and through the valorisation of this labour. Indeed, we see several implications for practitioners seeking to maintain a vibrant affective commons through Coworking arrangements (see also Figure 1).

The first is to clarify the conceptual story about the sources and processes of value creation through Coworking arrangements. If the atmosphere is a collective product of the affective labour of Coworkers, it is important that participants at least understand and, ideally, share this perspective on the logic of collective action. The theoretical account presented above treats the rituals and practices of Coworking as processes of commoning, rather than simple matters of individual preference. Second, it is equally important that the value of these commoning practices is clarified at the point where new members join a Coworking space, such that expectations about individual contributions to the common project may be clearly articulated. If access to a commons can simply be purchased through a market transaction, without comprehension and commitment to the processes of commoning and engagement by which such a community is sustained, then this will less likely result in the ongoing labour vital for the renewal of an affective commons. Third, developing methods of monitoring the 'health' of an affective commons are urgently needed. This will likely involve encouraging and cultivating a sensitivity towards affect, and legitimising discussions about the subtle ways an affective commons might be perturbed. Fourth, developing methods for acknowledging contributions to the health of the commons, and perhaps even 'graduated sanctions' (Ostrom, 1990: 90) against actions that negatively impact the commons ought to be pursued. Of course, each is likely to be challenging, but the literature is clear that commons are most likely to be sustained when community 


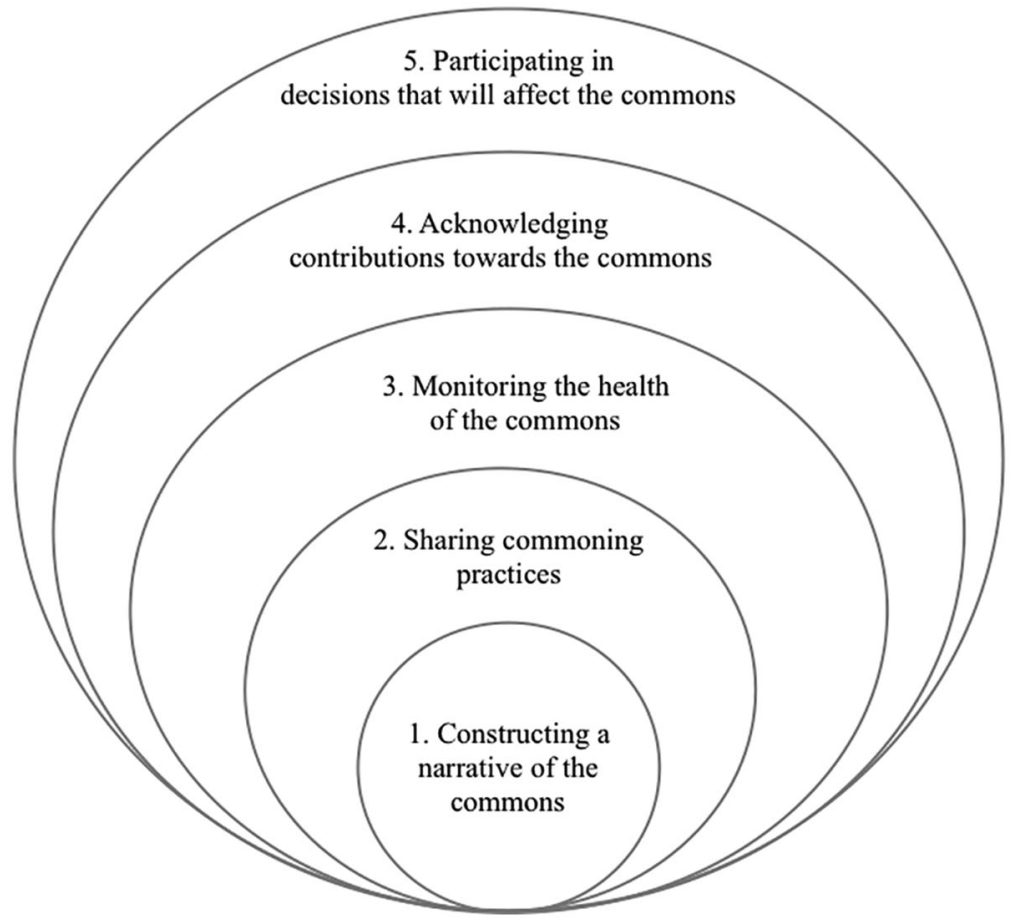

Figure I. Five principles towards the management and governance of an affective commons.

members view their own interests as aligned with the ongoing health of shared resources, and are dissuaded from the possibilities of free-riding or eroding these resources. Finally, given that our view of an affective commons is dependent on the commitment of the community itself, it is important to develop and provide novel methods of meaningfully participating in decision-making processes that will affect the community and its space. Importantly, such 'collective choice arrangements' (Ostrom, 1990: 90) are an essential means of retaining the legitimacy of a Coworking arrangement as a commons oriented project.

Following Ostrom (1990), we propose these five ideas as general principles for curating or sustaining an affective commons, even as we acknowledge that identifying the most appropriate modes of their enactment will depend on the specific features and constraints of each individual context. We also advance these principles with some caution, as any situated attempt to implement them in support of a vibrant affective commons will undoubtedly require a delicate, curatorial approach, just as any crudely instrumental or managerial application will likely corrode the organic sociality and affective tone that is an important source of the ongoing appeal of Coworking. ${ }^{3}$ We also refrain here from a detailed discussion of the structure of authority required to bootstrap the systems, logics or governance practices that might give rise to such a commons in the first place. Nevertheless, we note that the most widely acclaimed examples of digital information 
commons, Wikipedia and Linux, are governed by non-profit foundations, and we suspect that non-profit or cooperative legal structures are the most appropriate fit for cultivating and maintaining a thriving affective commons over time, even if significant entrepreneurial efforts of a few individuals are required to establish the process. As a first step, we hope our notion of an affective commons might offer greater clarity and legitimacy to popular expressions of the ways Coworkers sustain a 'vibe' or 'scene', even if the more precise questions of how to intentionally organise or curate these qualities require further work. This gap, however, between the intuitive sense of one's affective contribution to a common atmosphere, and the standard methods of acknowledging and valuing inputs to an enterprise, offers an explanation for the felt sense of ambivalence towards Coworking noted above, while gesturing towards the commoning processes by which this ambivalence might be mitigated.

\section{Conclusion}

Immaterial labour, and the digital technologies that have enabled knowledge work to become uncoupled from traditional sites of production, have inspired significant changes in the nature of work, and the modes of organising germane to it. This transition is marked as much by the prominence of affects as information, such that affective labour is as crucial to the constitution of appealing atmospheres as it is to the organisation of professional relationships and services. Coworking exemplifies the convergence of these trends, but despite the early interest in the model as a novel means of organising nonstandard work, many empirical accounts have emphasised ambivalent attitudes towards Coworking among participants. We have argued that this ambivalence logically stems from the prevailing organising structure of Coworking itself.

Prior literature has found that much of the appeal of Coworking lies in the affective quality of Coworking atmospheres, often realised by Coworkers as a feeling of community. Atmospheres give social and material form to structures of feeling. They are coconstituted by Coworkers themselves as manifest stores of action-potential that mediate dispositions and agencies within Coworking environments. This is why we have conceptualised these atmospheres as a shared resource, as the product of pooled affective labour. Insofar as commons are shared resources that a community jointly consumes and/or produces, they require unique institutional arrangements tailored to the nature of the resources and communities they comprise or sustain in order to support their ongoing viability. Managing a commons always requires a community to develop institutional norms to navigate the social dilemmas generated within that commons. With respect to Coworking, the key is to elaborate the community arrangements that might sustain a dense and vibrant affective commons by which truly novel forms of shared value might be sustained. We have outlined here five principles that ought to guide efforts to identify the most appropriate governance arrangements to support those commoning efforts by which an affective commons might come to thrive. The most critical step in our view is to first acknowledge the value of these commoning efforts in the shared vitality of Coworking arrangements, in the expression of an affective commons. This may also provide a tonic for the ambivalence towards Coworking so routinely described by participants as they jointly labour. 


\section{Acknowledgements}

The authors would like to gratefully acknowledge the three anonymous Human Relations reviewers and associate editor Timothy Kuhn for their constructive feedback on earlier drafts of this manuscript. We also would like to thank Adam Arvidsson, Alessandro Gandini, Alberto Cossu, Carolina Bandinelli and other attendees of the Post-Startup Cultures workshop at the University of Naples Federico II, Italy in 2018 for their critical feedback on the ideas in this article.

\section{Funding}

The authors received no financial support for the research, authorship and/or publication of this article.

\section{ORCID iD}

Julian Waters-Lynch (iD https://orcid.org/0000-0002-2422-4864

\section{Notes}

1 The term 'Coworkers' in this article refers specifically to the participants of Coworking spaces rather than its more general use as a synonym for colleagues.

2 The majority of research that notes this ambivalence towards Coworking features Coworking spaces that are privately owned. There are a few examples of studies that include cooperative or non-profit Coworking spaces (e.g. Avdikos and Iliopoulou, 2019; De Peuter et al., 2017), and these tend to highlight different sets of problems.

3 Indeed, there is much debate regarding the extent to which affects may be amenable to modification, direction, manipulation or 'channelling' (see Cameron, 2018; Gregg and Seigworth, 2010; Massumi, 2018). What seems beyond question, however, are the array of actors making sustained attempts to achieve this kind of affective control (see Gregg, 2018). We believe that kindling further debate on this matter would be a fruitful direction for research on affect and organisational studies. We also see parallels with past debates within management studies regarding theories of communities of practice, especially critical response to managerialist attempts to instrumentalise the concept (see Fox, 2000; Handley et al., 2006; Lave, 2008; Roberts, 2006).

\section{References}

Acquier A, Daudigeos T and Pinkse J (2017) Promises and paradoxes of the sharing economy: An organizing framework. Technological Forecasting and Social Change 125(Dec 2017): 1-10.

Adams JS (1965) Inequity in social exchange. In: Berkowitz L (ed.) Advances in Experimental Social Psychology, vol. 2. New York: Academic Press, 267-299.

Anderson B (2009) Affective atmospheres. Emotion, Space and Society 2(2): 77-81.

Anderson B (2014) Encountering Affect: Capacities, Apparatuses, Conditions. New York, NY: Routledge.

Anderson B (2016) Neoliberal affects. Progress in Human Geography 40(6): 734-753.

Arvidsson A (2019) Capitalism and the commons. Theory, Culture and Society. Epub ahead of print 25 August 2019. DOI: 10.1177/0263276419868838.

Ashcraft KL (2017) 'Submission' to the rule of excellence: Ordinary affect and precarious resistance in the labor of organization and management studies. Organization 24(1): 36-58. 
Avdikos V and Iliopoulou E (2019) Community-led Coworking spaces: From co-location to collaboration and collectivization. In: Gill R, Pratt AC and Virani TE (eds) Creative Hubs in Question. Cham: Palgrave Macmillan, 111-129.

Axelrod R and Dion D (1988) The further evolution of cooperation. Science 242(4884): 1385-1390.

Axelrod R and Hamilton WD (1981) The evolution of cooperation. Science 211(4489): 1390-1396.

Bandinelli C (2019) The production of subjectivity in neoliberal culture industries: The case of Coworking spaces. International Journal of Cultural Studies. Epub ahead of print 17 October 2019. DOI: 10.1177/1367877919878449.

Bauman Z (2001) Community: Seeking Safety in an Insecure World. Cambridge: Polity Press.

Benkler Y (2002) Coase's penguin, or Linux and The Nature of the Firm. Yale Law Journal 112(3): 369-446.

Benkler Y (2006) The Wealth of Networks: How Social Production Transforms Markets and Freedom. New Haven, CT: Yale University Press.

Benkler Y (2017) Peer production, the commons, and the future of the firm. Strategic Organization 15(2): 264-274.

Benkler Y and Nissenbaum H (2006) Commons-based peer production and virtue. Journal of Political Philosophy 14(4): 394-419.

Beverungen A, Böhm S and Land C (2015) Free labour, social media, management: Challenging Marxist organization studies. Organization Studies 36(4): 473-489.

Bille M, Bjerregaard P and Sørensen TF (2015) Staging atmospheres: Materiality, culture, and the texture of the in-between. Emotion, Space and Society 15(May 2015): 31-38.

Bissell D (2010) Passenger mobilities: Affective atmospheres and the sociality of public transport. Environment and Planning D: Society and Space 28(2): 270-289.

Blackman L (2019) Haunted Data: Affect, Transmedia, Weird Science. London: Bloomsbury.

Blagoev B, Costas J and Kärreman D (2019) 'We are all herd animals': Community and organizationality in coworking spaces. Organization 26(6): 894-916.

Bouncken RB and Reuschl AJ (2018) Coworking-spaces: How a phenomenon of the sharing economy builds a novel trend for the workplace and for entrepreneurship. Review of Managerial Science 12(1): 317-334.

Cameron A (2018) Affected Labour in a Cafe Culture: The Atmospheres and Economics of 'Hip' Melbourne. London: Routledge.

Capdevila I (2014) Coworkers, Makers, and Fabbers: Global, Local and Internal Dynamics of Innovation in Localized Communities in Barcelona. Canada: HEC Montreal.

Capdevila I (2018) Knowing communities and the innovative capacity of cities. City, Culture and Society 13(June 2018): 8-12.

Child J and McGrath RG (2001) Organizations unfettered: Organizational form in an informationintensive economy. Academy of Management Journal 44(6): 1135-1148.

Cnossen B and Bencherki N (2018) The role of space in the emergence and endurance of organizing: How independent workers and material assemblages constitute organizations. Human Relations 72(6): 1057-1080.

Coffey J, Farrugia D, Adkins L, et al. (2018) Gender, sexuality, and risk in the practice of affective labour for young women in bar work. Sociological Research Online 23(4): 728-743.

De Angelis M (2017) Omnia Sunt Communia: On the Commons and the Transformation to Postcapitalism. New York: Zed Books.

DeGuzman GV and Tang AI (2011) Working in the Unoffice: A Guide to Coworking for Indie Workers, Small Businesses, and Nonprofits. San Francisco, CA: Night Owls Press.

De Peuter G, Cohen NS and Saraco F (2017) The ambivalence of Coworking: On the politics of an emerging work practice. European Journal of Cultural Studies 20(6): 687-706. 
Dowling E (2012) The waitress: On affect, method and (re) presentation. Cultural Studies, Critical Methodologies 12(2): 109-117.

Dowling E, Nunes R and Trott B (2007) Immaterial and affective labour: Explored. Ephemera: Theory and Politics in Organization 7(1): 1-7.

Duff C (2014) Assemblages of Health: Deleuze's Empiricism and the Ethology of Life. Australia: Springer.

Fotaki M, Kenny K and Vachhani SJ (2017) Thinking critically about affect in organization studies: Why it matters. Organization 24(1): 3-17.

Fox S (2000) Communities of practice, Foucault and actor-network theory. Journal of Management Studies 37(6): 853-868.

Frischmann BM (2012) Infrastructure: The Social Value of Shared Resources. Oxford, UK: Oxford University Press.

Frischmann BM, Madison MJ and Strandburg KJ (eds) (2014) Governing Knowledge Commons. Oxford: Oxford University Press.

Gandini A (2015) The rise of Coworking spaces: A literature review. Ephemera 15(1): 193-205.

Garrett LE, Spreitzer GM and Bacevice PA (2017) Co-constructing a sense of community at work: The emergence of community in Coworking spaces. Organization Studies 38(6): 821-842.

Gerdenitsch C, Scheel TE, Andorfer J, et al. (2016) Coworking spaces: A source of social support for independent professionals. Frontiers in Psychology 7(April 2016): 1-12.

Gill R and Pratt A (2008) In the social factory? Immaterial labour, precariousness and cultural work. Theory, Culture and Society 25(7-8): 1-30.

Gregg M (2018) From careers to atmospheres. In: Schaefer S, Andersson M, Bjarnason E, et al. (eds) Working and Organizing in the Digital Age. Lund: The Pufendorf Institute for Advanced Studies, Lund University Press, 83-94.

Gregg M and Lodato T (2018) Managing community: Coworking, hospitality and the future of work. In: Röttger-Rössler B and Slaby J (eds) Affect in Relation: Families, Places, Technologies. London: Routledge, 175-196.

Gregg M and Seigworth GJ (eds) (2010) The Affect Theory Reader. Durham, NC: Duke University Press.

Handley K, Sturdy A, Fincham R, et al. (2006) Within and beyond communities of practice: Making sense of learning through participation, identity and practice. Journal of Management Studies 43(3): 641-653.

Hardin G (1968) The tragedy of the commons. Science 162(3859): 1243-1248.

Hardt M (1999) Affective labor. Boundary 2 26(2): 89-100.

Hardt M and Negri A (2000) Empire. Cambridge, MA: Harvard University Press.

Hardt M and Negri A (2004) Multitude: War and Democracy in the Age of Empire. London: Penguin.

Hesmondhalgh D and Baker S (2011) Creative Labour: Media Work in Three Cultural Industries. London: Routledge.

Hochschild AR (2012 [1983]) The Managed Heart: Commercialization of Human Feeling. Berkeley, CA: University of California Press.

Hoedemaekers C (2017) Creative work and affect: Social, political and fantasmatic dynamics in the labour of musicians. Human Relations 71(10): 1348-1370.

Huseman R, Hatfield J and Miles E (1987) A new perspective on equity theory: The equity sensitivity construct. The Academy of Management Review 12(2): 222-234.

Iszatt-White M (ed.) (2013) Leadership as Emotional Labour: Management and the 'Managed Heart'. London: Routledge. 
Jakonen M, Kivinen N, Salovaara P, et al. (2017) Towards an economy of encounters? A critical study of affectual assemblages in Coworking. Scandinavian Journal of Management 33(4): 235-242.

Jarvis H and Pratt AC (2006) Bringing it all back home: The extensification and 'overflowing' of work: The case of San Francisco's new media households. Geoforum 37(3): 331-339.

Jones AM (2013) The Fifth Age of Work: How Companies Can Redesign Work to Become More Innovative in a Cloud Economy. Portland, OR: Night Owls Press.

Jones D, Sundsted T and Bacigalupo T (2009) I'm Outta Here! How Coworking is Making the Office Obsolete. Austin, TX: Not an MBA Press.

Kenny K and Fotaki M (eds) (2014) The Psychosocial and Organization Studies: Affect at Work. Basingstoke: Palgrave Macmillan.

Knudsen BT and Stage C (2015) Affective Methodologies. Basingstoke: Palgrave Macmillan.

Kojo I and Nenonen S (2017) Evolution of co-working places: Drivers and possibilities. Intelligent Buildings International 9(3): 164-175.

Kollock P (1998) Social dilemmas: The anatomy of cooperation. Annual Review of Sociology 24(1): 183-214.

Kuhn T, Ashcraft KL and Cooren F (2017) The Work of Communication: Relational Perspectives on Working and Organizing in Contemporary Capitalism. New York: Routledge.

Lave J (2008) Epilogue: Situated learning and changing practice. In: Amin A and Roberts J (eds) Community, Economic Creativity, and Organization. Oxford: Oxford University Press, 283-296.

Lazzarato M (1996) Immaterial labor. In: Virno P and Hardy M (eds) Radical Thought in Italy: A Potential Politics. Minneapolis, MN: University of Minnesota Press, 133-147.

Lee D (2019) Creative hubs, cultural work and affective economies: Exploring 'unspeakable' experiences for young cultural workers. In: Gill R, Pratt AC and Virani TE (eds) Creative Hubs in Question. Cham: Palgrave Macmillan, 69-88.

Lessig L (2002) The Future of Ideas: The Fate of the Commons in a Connected World. New York, NY: Vintage.

Lessig L (2003) The creative commons. Florida Law Review 55(3): 763-777.

Madison MJ, Frischmann BM and Strandburg KJ (2009) Constructing commons in the cultural environment. Cornell Law Review 95(4): 657-709.

Martin CJ (2016) The sharing economy: A pathway to sustainability or a nightmarish form of neoliberal capitalism? Ecological Economics 121(Jan 2016): 149-159.

Massumi B (2018) 99 Theses on the Revaluation of Value: A Postcapitalist Manifesto. Minneapolis, MN: University of Minnesota Press.

Merkel J (2015) Coworking in the city. Ephemera 15(2): 121-139.

Merkel J (2017) Coworking and innovation. In: Bathelt H, Cohendet P, Henn S, et al. (eds) The Elgar Companion to Innovation and Knowledge Creation. Cheltenham: Edward Elgar Publishing, 570-586.

Merkel J (2019) 'Freelance isn't free': Co-working as a critical urban practice to cope with informality in creative labour markets. Urban Studies 56(3): 526-547.

Morgan G and Woodriff J (2019) Herding cats: Co-work, creativity and precarity in inner Sydney. In: Gill R, Pratt AC and Virani TE (eds) Creative Hubs in Question. Cham: Palgrave Macmillan, 29-50.

Mühlhoff R and Slaby J (2018) Immersion at work: Affect and power in post-Fordist work cultures. In: Röttger-Rössler B and Slaby J (eds) Affect in Relation: Families, Places, Technologies. London: Routledge, 155-174.

Oksala J (2016) Affective labor and feminist politics. Signs: Journal of Women in Culture and Society 41(2): 281-303. 
Olson M (1965) The Logic of Collective Action: Public Goods and the Theory of Groups. Cambridge, MA: Harvard University Press.

Ostrom E (1990) Governing the Commons: The Evolution of Institutions for Collective Action. Cambridge: Cambridge University Press.

Ostrom E (2000) Collective action and the evolution of social norms. Journal of Economic Perspectives 14(3): 137-158.

Ostrom V and Ostrom E (1977) Public goods and public choices. In: Savas ES (ed.) Alternatives for Delivering Public Services: Toward Improved Performance. Boulder, CO: Westview Press, 7-49.

Papacharissi Z (2015) Affective Publics: Sentiment, Technology, and Politics. Oxford: Oxford University Press.

Pile S (2010) Emotions and affect in recent human geography. Transactions of the Institute of British Geographers 35(1): 5-20.

Richardson L (2015) Performing the sharing economy. Geoforum 67(Dec 2015): 121-129.

Richardson L (2017) Sharing as a postwork style: Digital work and the co-working office. Cambridge Journal of Regions, Economy and Society 10(2): 297-310.

Rifkin J (2014) The Zero Marginal Cost Society: The Internet of Things, the Collaborative Commons, and the Eclipse of Capitalism. New York, NY: Palgrave Macmillan.

Roberts J (2006) Limits to communities of practice. Journal of Management Studies 43(3): 623-639.

Scholz T (2016) Platform Cooperativism: Challenging the Corporate Sharing Economy. New York: Rosa Luxemburg Stiftung.

Sennett R (2007) The Culture of the New Capitalism. London: Yale University Press.

Spinuzzi C (2012) Working alone together. Coworking as emergent collaborative activity. Journal of Business and Technical Communication 26(4): 399-441.

Spinuzzi C, Bodrožić Z, Scaratti G, et al. (2019) 'Coworking is about community': But what is 'community' in Coworking? Journal of Business and Technical Communication 33(2): $112-140$.

Stewart K (2007) Ordinary Affects. Durham, NC: Duke University Press.

Sumartojo S and Pink S (2018) Atmospheres and the Experiential World: Theory and Methods. London: Routledge.

Thibaud J (2015) The backstage of urban ambiances: When atmospheres pervade everyday experience. Emotion, Space and Society 15(May 2015): 39-46.

Vannini P (ed.) (2015) Non-Representational Methodologies: Re-Envisioning Research. New York, NY: Routledge.

Vidaillet B and Bousalham Y (2018) Coworking spaces as places where economic diversity can be articulated: Towards a theory of syntopia. Organization. Epub ahead of print 30 August 2018. DOI: $10.1177 / 1350508418794003$.

Waters-Lynch J (2018) A theory of Coworking: Entrepreneurial communities, immaterial commons and working futures. PhD Thesis, RMIT University, Australia.

Weeks K (2011) The Problem with Work: Feminism, Marxism, Antiwork Politics, and Postwork Imaginaries. Durham, NC: Duke University Press. 
Julian Waters-Lynch is Industry Fellow in Entrepreneurship and Innovation at the School of Management at RMIT University, Melbourne, Australia. Waters-Lynch's research explores interactions between emerging technology, the changing character of knowledge work and the relational organisation of entrepreneurial learning. Waters-Lynch's doctoral thesis comprised an ethnography of the pioneering Coworking communities in Melbourne, Australia. [Email: julianmaurice.waterslynch@rmit.edu.au]

Cameron Duff is Associate Professor of Management at the School of Management at RMIT University, Melbourne, Australia. Duff's research explores the role of social innovation and social entrepreneurship in responding to complex health and social problems in urban settings. Duff has explored these themes in qualitative studies of housing insecurity, addiction and mental illness in Australia and Canada. [Email: cameron.duff@rmit.edu.au] 